05

\title{
Экспериментальное исследование влияния магнитного поля удлиненного соленоида на растяжение металлических кумулятивных струй
}

\author{
(C) С.В. Федоров, А.В. Бабкин, В.М. Маринин \\ Московский государственный технический университет им. Н.Э. Баумана, \\ 105005 Москва, Россия \\ e-mail: sergfed-64@mail.ru
}

Поступило в Редакцию 3 октября 2019 г.

В окончательной редакции 3 октября 2019 г.

Принято к публикации 1 ноября 2019 г.

\begin{abstract}
Представлены результаты экспериментального исследования влияния продольного магнитного поля удлиненного соленоида на растяжение металлических кумулятивных струй в свободном полете. В опытах использовались кумулятивные заряды диаметром $50 \mathrm{~mm}$ с медной конической облицовкой. Параметры разрядного контура соленоида с емкостным накопителем энергии были таковы, что характерные времена достижения максимума магнитной индукции составляли порядка $100 \mu \mathrm{s}$. При реализованных в экспериментах параметрах магнитных полей с максимальным значением индукции до 10 Т было зафиксировано небольшое увеличение глубины пробития стальной преграды, не превышавшее 10\%. Обсуждены возможные причины большого расхождения полученных результатов с результатами аналогичных экспериментов.
\end{abstract}

Ключевые слова: взрыв, кумулятивный заряд, кумулятивная струя, пробивное действие, пластическая неустойчивость, магнитное поле, соленоид.

DOI: 10.21883/JTF.2020.04.49089.326-19

\section{Введение}

При взрывном обжатии тонких металлических оболочек формируются высокоскоростные кумулятивные струи (КС), обладающие высокой пробивной способностью [1-3]. Обжатие оболочки происходит под действием давления продуктов детонации заряда взрывчатого вещества, в полости которого размещается оболочка [4]. В свободном полете КС сначала удлиняются с сохранением сплошности, а затем распадаются на отдельные безградиентные элементы [5-7]. Суммарная длина элементов, образовавшихся после разрыва КС, определяет предельное пробивное действие кумулятивного заряда (К3) $[4,8,9]$.

При удлинении в свободном полете высокоградиентных КС из пластичных металлов на начальной стадии деформирование струи происходит равномерно c сохранением близкой к цилиндрической формы [5]. В последующем на струе развивается неустойчивость, реализующаяся в форме появления и развития многочисленных шеек [10-12]. В процессе развития шеек происходит перераспределение осевой скорости по длине струи, приводящее в итоге к формированию отдельных безградиентных элементов и к прекращению увеличения длины струи. Движущими факторами этого процесса являются внутренние силы, возникающие в струе вследствие наличия у ее материала прочностных свойств (пластическая неустойчивость).

С помощью электромагнитных воздействий, осуществляемых на различных стадиях функционирования
КЗ, можно оказать влияние на его пробивное действие. К снижению пробития КЗ приводит создание в его облицовке перед подрывом магнитного поля достаточной интенсивности, нарушающее нормальное струеобразование [13-15]. Пробивная способность КС может быть также снижена за счет пропускания по ней перед взаимодействием с преградой мощного импульса электрического тока $[16,17]$. При мощном токовом воздействии развивается магнитогидродинамическая неустойчивость КС $[18,19]$, ускоряющая ее распад на отдельные элементы, а также наблюдается радиальное диспергирование материала струи [20].

В качестве электромагнитного воздействия, способного привести к повышению пробивного действия КЗ, рассматривается воздействие на КС в свободном полете продольного магнитного поля [21-26]. В экспериментax [25] магнитное поле с максимальной индукцией $1.7 \mathrm{~T}$ создавалось на значительном удалении от К3, где КС уже распадалась на отдельные элементы. Зафиксированный при этом значительный прирост глубины пробития преграды объясняется в [25] снижением в магнитном поле скорости бокового дрейфа элементов разорванной КС, который всегда существует вследствие технологических погрешностей изготовления КЗ $[27,28]$. В экспериментах [26] с воздействием магнитного поля примерно той же интенсивности $(1.7 \mathrm{~T})$ на КС в ближней от КЗ зоне, где она еще деформируется с сохранением сплошности, было также получено значительное увеличение пробивного действия КЗ, связываемое с замедлением развития пластической неустойчивости КС 
при растяжении в магнитном поле [21,22]. Кроме того, авторы [26] обратили внимание на небольшой прирост скорости головной части КС после ее выхода из магнитного поля, чему в [29] ими было предложено отдельное объяснение.

Эксперименты по воздействию магнитного поля на растягивающуюся КС, подобные представленным в [26], проводились в МГТУ им. Н.Э. Баумана в начале 90$\mathrm{x}$ годов прошлого века [30]. Однако зафиксированный в них эффект увеличения глубины пробития КЗ был во много раз слабее. В связи с незначительностью достигнутого эффекта ранее была опубликована только небольшая часть результатов этих экспериментов [30] без подробностей их проведения. Публикация работы [26] о получении в сопоставимых условиях гораздо большего прироста пробития КЗ побудила вновь вернуться к выполненным ранее аналогичным экспериментам и проанализировать их проведение более подробно с тем, чтобы установить возможную причину большого расхождения в экспериментальных результатах $[26,30]$.

\section{Физические предпосылки}

Целью проводившихся экспериментальных исследований являлось определение возможности увеличения предельного удлинения КС и ее пробивного действия при растяжении в магнитном поле. Направленное на достижение этого эффекта воздействие магнитного поля должно осуществляться в той области пространства и в тот интервал времени, где и когда происходит равномерное растяжение КС или развитие неустойчивости на КС до разрыва струи на отдельные элементы. Стабилизирующее влияние магнитного поля на процесс удлинения КС связывается с появлением в струе дополнительных электромагнитных усилий, препятствующих развитию шеек $[21,22]$.

Предполагаемые физические механизмы подавления развития шеек на КС продольным магнитным полем таковы (рис. 1). На начальной стадии движения участков КС в области магнитного поля происходит диффузия (проникновение) поля в материал струи, и в ней возникают азимутальные вихревые токи. Первоначально магнитное поле и токи сконцентрированы в тонком поверхностном слое струи (скин-слое), чему способствует достаточно высокая проводимость ее материала. В том же поверхностном слое сконцентрированы и электромагнитные силы, и их воздействие на КС эквивалентно распределенному по поверхности струи магнитному давлению (рис. $1, a$ ). Стабилизирующий эффект в этом случае основан на ослаблении магнитного поля в областях развивающихся шеек и его усилении в областях выпучин (магнитное поле как бы придавливает струю по выпуклостям на поверхности, чем тормозится развитие шеек).

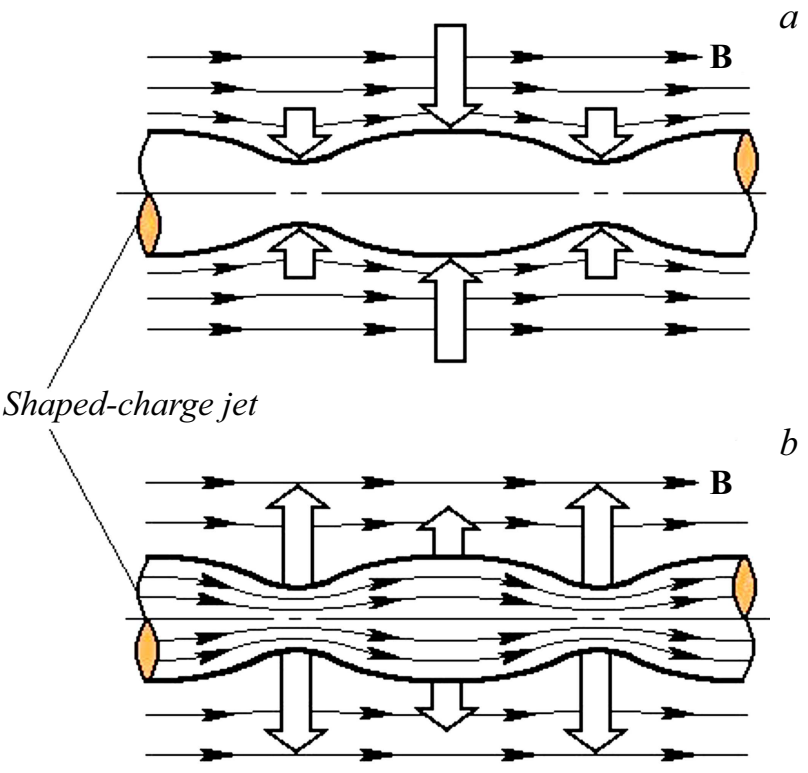

Рис. 1. Физические механизмы замедления развития пластической неустойчивости металлических КС при деформировании в продольном магнитном поле.

После полного проникновения магнитного поля в материал струи вступает в действие другой возможный механизм стабилизации, являющийся следствием проявления известного в магнитной гидродинамике эффекта „накачки“ магнитного поля в быстродеформируемых проводящих материалах [31]. Так как растяжение КС сопровождается большими осевыми деформациями, продольное магнитное поле в струе, в соответствии с эффектом его „вмороженности“ в проводящее вещество, тяготеет к усилению [32,33], и на определенной стадии превышает внешнее магнитное поле. В таком случае объемные электромагнитные силы направлены радиально от оси, как бы распирая струю (рис. 1,b). Шейкообразование связано с локализацией деформирования в областях шеек, где деформации удлинения больше, чем на постепенно формирующихся безградиентных участках струи. Поэтому и магнитное поле в струе в областях шеек усиливается больше, а радиальные растягивающие силы увеличены по отношению к будущим безградиентным участкам. Последнее должно вести к замедлению шейкообразования, нежелательного с точки зрения увеличения длины струи.

\section{Постановка экспериментов}

Воздействие магнитного поля на КС осуществлялось с помощью удлиненного соленоида, расположенного перед КЗ на пути движения струи (рис. 2,a). Опыты проводились с КЗ диаметром $d_{0}=50 \mathrm{~mm}$ с медной конической облицовкой с углом раствора $50^{\circ}$. Соленоиды делались многовитковыми с различным исполнением в вариантах для одноразового и многоразового применения 


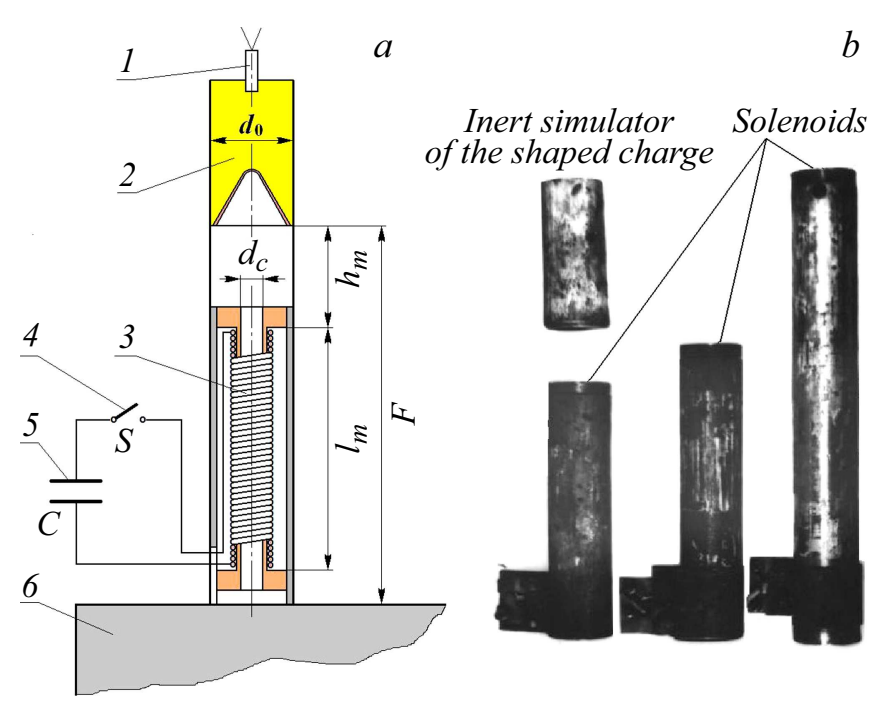

Рис. 2. Схема проведения экспериментов с воздействием магнитного поля на КС $(a)$ и варианты многоразовых соленоидов $(b)$, использовавшихся для создания магнитного поля: $1-$ электродетонатор; 2 - кумулятивный заряд; 3 - соленоид; 4 - коммутатор; 5 - конденсаторная батарея; $6-$ стальная преграда.

(рис. 2, b). Материалом корпуса одноразовых соленоидов являлся текстолит. У соленоидов многоразового использования корпус был стальным и не разрушался при взрыве КЗ. Продольное магнитное поле создавалось в объеме цилиндрического канала длиной $l_{m}$ от 110 до $330 \mathrm{~mm}$ при удалении ближней границы области воздействия от основания КЗ на $h_{m}=70 \mathrm{~mm}$. В качестве источника электрической энергии использовалась конденсаторная батарея (рис. 2,a). Ее разряд на соленоид инициировался быстродействующим взрывным коммутатором, действие которого основывалось на сварке взрывом алюминиевых пластин-контактов. Коммутация электрической цепи осуществлялась с некоторым упреждением относительно подрыва КЗ, необходимым для нарастания индукции магнитного поля в полости соленоида.

Разрядный ток контролировался с помощью пояса Роговского, а индукция магнитного поля в полости соленоида - с помощью индуктивных датчиков. Индуктивные датчики размещались в полости соленоидов только в тарировочных опытах по определению параметров создаваемых соленоидами магнитных полей. В опытах с подрывом КЗ полость соленоида была полностью свободна для прохождения КС, а достижение необходимых параметров магнитного поля контролировалось косвенно по величине разрядного тока на основании предварительно установленной взаимосвязи между силой тока $J$ и магнитной индукцией $B$ в полости соленоида. На рис. 3 показаны типичные примеры регистраций с обоих датчиков в тарировочном опыте с одним из соленоидов многоразового использования. Запаздывание по времени в достижении максимума индукции магнитного поля в полости соленоида по отношению к максимуму разрядного тока объясняется наличием у соленоида металлического корпуса, в котором при разряде индуцируются собственные вихревые токи.

Время задержки $\tau_{s}$ подрыва КЗ относительно момента срабатывания взрывного коммутатора разрядной цепи определялось на основании сопоставления пространственно-временной диаграммы движения КС и закона изменения во времени магнитного поля в полости соленоида (рис. 4). Из проиллюстрированного на рис. 4 примера видно, что индукция магнитного поля достигает максимального значения $B_{m}$ за время $t_{m}$ примерно $185 \mu \mathrm{s}$. Входу головной части КС со скоростью $v_{z h}=8 \mathrm{~km} / \mathrm{s}$ в полость соленоида соответствует момент времени от подрыва КЗ около $25 \mu \mathrm{s}$, а выходу из соленоида хвостовой части КС со скоростью $v_{z t}=2 \mathrm{~km} / \mathrm{s}-$ около $145 \mu \mathrm{s}$. При времени задержки $\tau_{s}=110 \mu \mathrm{s}$ в течение всего времени движения КС через полость соленоида $\tau_{j}$, составляющего примерно $120 \mu \mathrm{s}$, индукция магнитного поля близка к максимальной (рис. 4). По отношению к КС вследствие очень высокой скорости ее движения такое магнитное поле является квазистационарным (по существу, постоянным), несмотря на достаточно высокую характерную частоту его изменения (порядка $10^{3} \mathrm{~Hz}$ ).

В опытах определялась глубина $L$ пробития КС, прошедшей через магнитное поле соленоида, стальной преграды, расстояние до которой от основания КЗ $F$ изменялось от 250 до $415 \mathrm{~mm}$ (рис. 2, $a$ ).
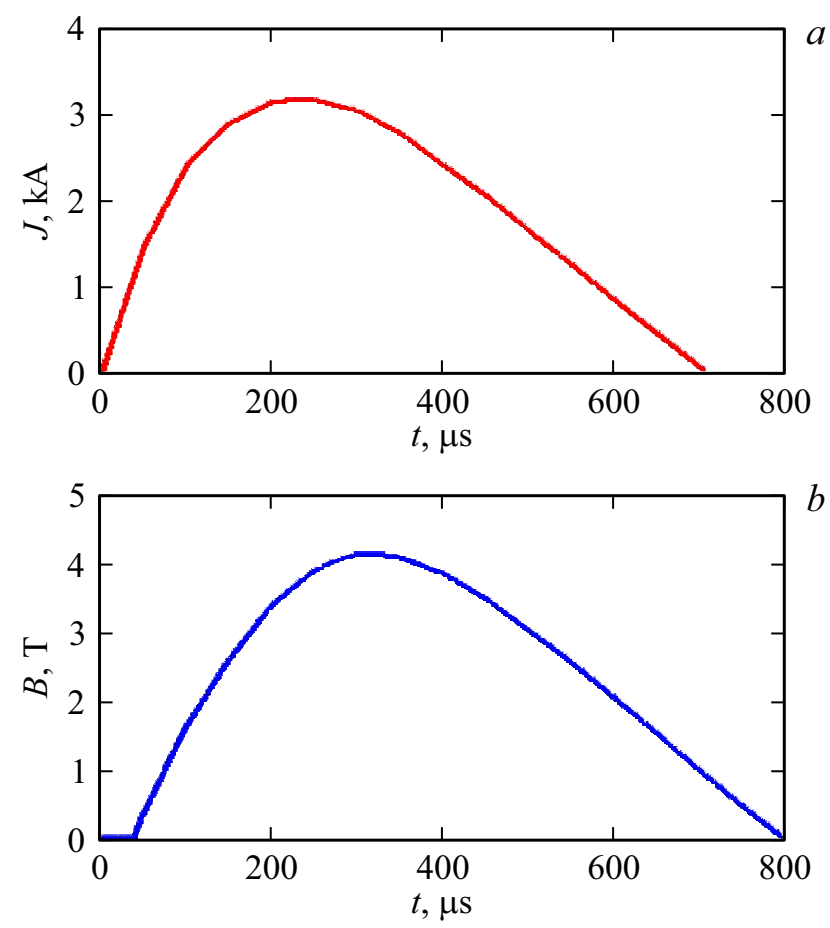

Рис. 3. Характерные кривые изменения разрядного тока (a) и индукции магнитного поля в полости соленоида $(b)$. 


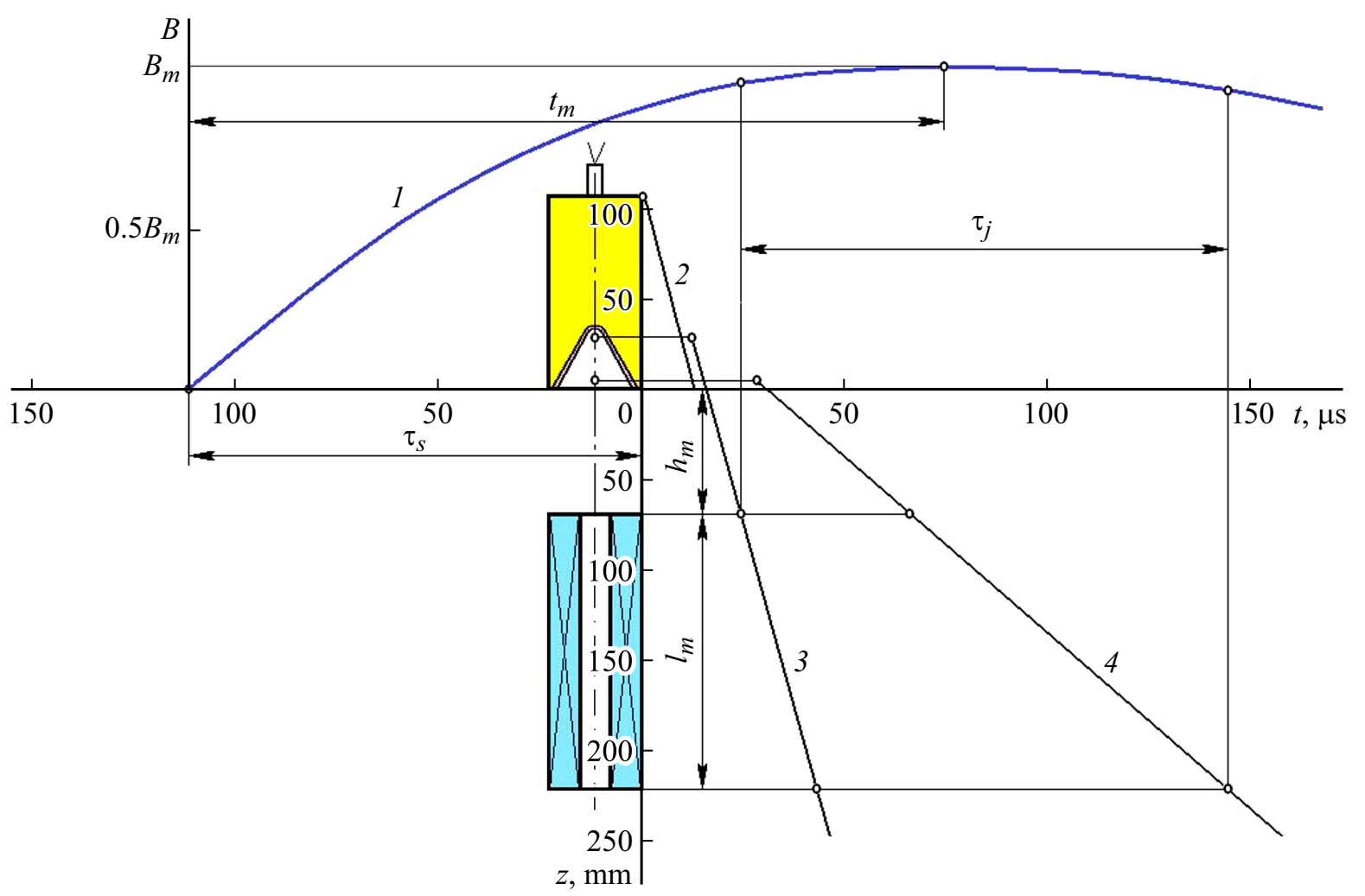

Рис. 4. Пространственно-временная диаграмма для определения времени задержки между коммутацией разрядной цепи соленоида и подрывом КЗ: 1 - изменение индукции магнитного поля в полости соленоида, 2 - распространение детонационной волны в КЗ, 3 - движение головного участка КС со скоростью $8 \mathrm{~km} / \mathrm{s}, 4$ - движение хвостового участка КС со скоростью $2 \mathrm{~km} / \mathrm{s}$.

\section{Результаты}

Диаметр канала для прохода КС $d_{c}$ (рис. 2,a) варьировался для соленоидов различного исполнения от 12 до $20 \mathrm{~mm}$. Так как реализация электромагнитного воздействия на КС связана с прохождением струи через длинный узкий канал (полость соленоида), где она может подвергнуться влиянию факторов чисто механической природы („скользящее“ столкновение со стенками канала, воздействие отражаемых ими ударных волн), предварительно была проведена серия экспериментов по выявлению „канальных“ эффектов. В этих экспериментах перед КЗ располагалась стальная цилиндрическая втулка со сквозным каналом, внешний диаметр которой для облегчения соосной установки с КЗ был равен диаметру заряда. Диаметры каналов для прохода КС составляли 10, 15 и $20 \mathrm{~mm}$, длина втулок в основной части опытов составляла $150 \mathrm{~mm}$, было проведено также несколько опытов с втулками длиной 100 и $200 \mathrm{~mm}$. Заряд отстоял от верхнего торца втулки на расстоянии от 50 до $120 \mathrm{~mm}$. Физическая картина процессов при кумулятивном взрыве с наличием перед КЗ втулки с узким каналом анализировалась с использованием оптической съемки (рис. 5).

На рис. 5, $а$ зафиксирован взрыв К3 в свободном пространстве (в отсутствие втулки): КЗ был установлен на стальной преграде на расстоянии $F=250 \mathrm{~mm}$ от нее с помощью трех проволочных стоек. Хорошо видны КС, опережающая в своем движении разлет продуктов детонации, и связанная с ее головной частью баллистическая ударная волна, создающая область свечения воздуха, движущуюся вместе с КС. Свечение, появляющееся в нижней части последнего кадра (рис. 5,a), возникает при соударении КС с преградой. Фоторегистрации на рис. 5, $b$ иллюстрируют процессы входа КС в канал и выхода из него для втулки длиной $100 \mathrm{~mm}$ с каналом диаметром $d_{c}=10 \mathrm{~mm}$, КЗ был расположен на расстоянии $50 \mathrm{~mm}$ от верхнего торца втулки.

По результатам экспериментов со стальными втулками было установлено, что для используемого КЗ диаметром $50 \mathrm{~mm}$ применение соленоидов с диаметром канала для прохода КС менее $10 \mathrm{~mm}$ нецелесообразно ввиду большой вероятности столкновений струи со стенками канала, приводящих к существенному снижению пробития (следует отметить, что при использовании втулок с каналом диаметром $10 \mathrm{~mm}$ пест в подавляющем большинстве случаев застревал в верхней части канала, чего не происходило при других диаметрах канала). При диаметрах канала больше $10 \mathrm{~mm}$ столкновения практически исключаются, и отрицательное влияние „канальных“ эффектов очень незначительно. Среднее по 4-5 опытам пробитие в отсутствие электромагнитного 

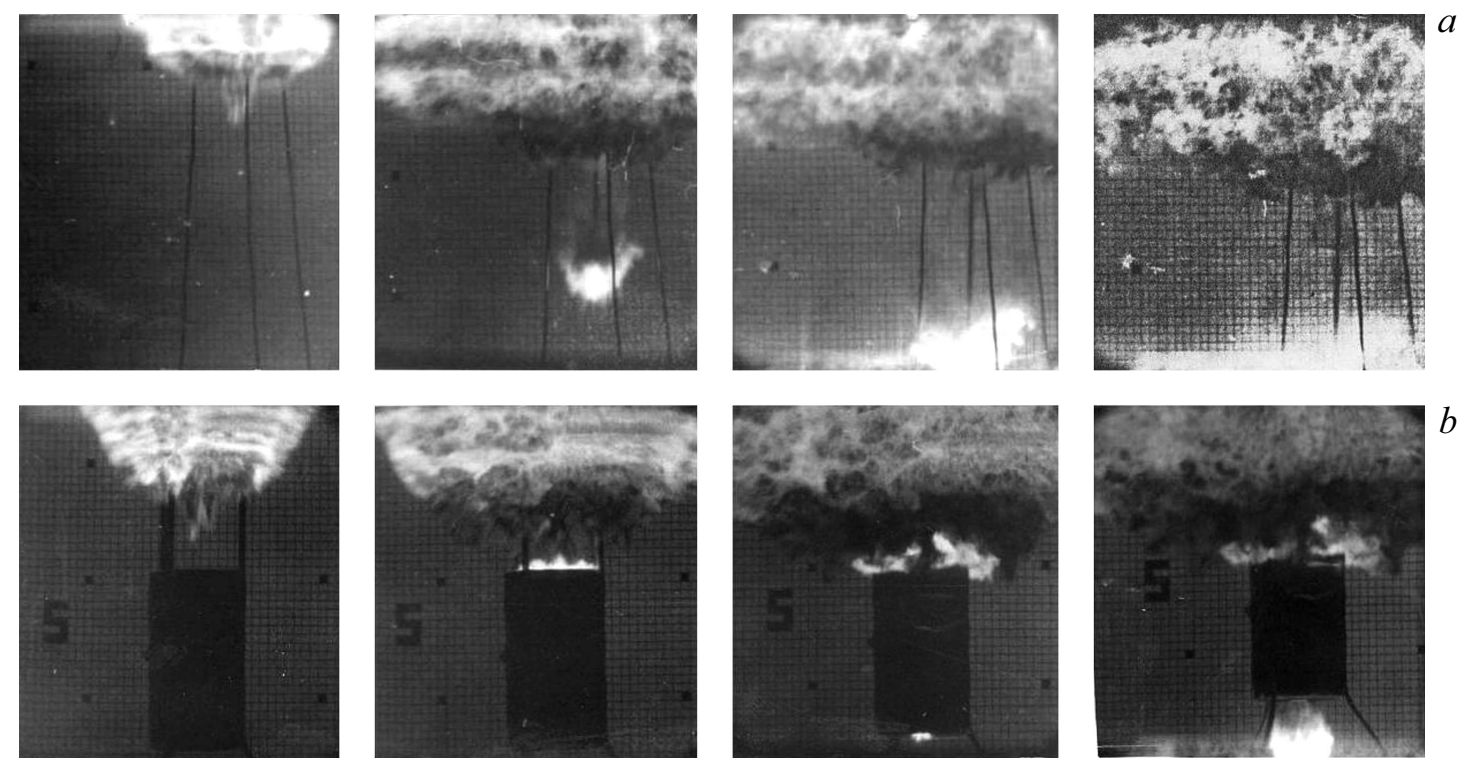

Рис. 5. Фоторегистрации взрыва КЗ в свободном пространстве $(a)$ и при размещении перед КЗ стальной втулки с узким каналом для прохода КС $(b)$.

Результаты экспериментов с воздействием магнитного поля удлиненных соленоидов на КС

\begin{tabular}{r|c|c|c|r|c}
\hline № & $F, \mathrm{~mm}$ & $l_{m}, \mathrm{~mm}$ & $t_{m}, \mu \mathrm{s}$ & $B_{m}, \mathrm{~T}$ & $L, \mathrm{~mm}$ \\
\hline 1 & 250 & 110 & 140 & 3.3 & 230 \\
2 & & & 200 & 5.4 & 265 \\
3 & & & 140 & 6.3 & 255 \\
4 & & & & 10.5 & 250 \\
5 & & & & 10.5 & 260 \\
6 & & 135 & 120 & 2.6 & 275 \\
7 & & 150 & 320 & 2.6 & 250 \\
8 & & & & 5.3 & 230 \\
9 & & & & 5.5 & 255 \\
10 & & & & 8.2 & 255 \\
11 & & & & 8.5 & 245 \\
12 & 280 & 180 & 210 & 2.0 & 235 \\
13 & & & & 2.7 & 240 \\
14 & 320 & & 170 & 5.5 & 210 \\
15 & 415 & 330 & 300 & 2.3 & 150 \\
16 & & & & 4.5 & 220 \\
17 & & & & 4.7 & 120
\end{tabular}

воздействия в случае втулок длиной $150 \mathrm{~mm}$ с диаметром канала $10 \mathrm{~mm}$ составляло $L=235 \mathrm{~mm}$ при лучшем результате $L=245 \mathrm{~mm}$. Для „свободного“ КЗ (в отсутствие втулки) среднее пробитие на соответствующем расстоянии заряда от преграды составляло $L=245 \mathrm{~mm}$ при лучшем результате $L=255 \mathrm{~mm}$.

Результаты экспериментов с воздействием магнитного поля соленоидов на растягивающуюся КС представлены в таблице, где приводятся расстояние от КЗ до преграды $F$, длина соленоида $l_{m}$, время выхода индукции магнитного поля в полости соленоида на максимум $t_{m}$, значение магнитной индукции в максимуме $B_{m}$ и глубина пробития КС стальной преграды $L$. Из таблицы видно, что существенного влияния на пробивное действие КС магнитное поле с индукцией до $10 \mathrm{~T}$ не оказывало. Однако практически во всех опытах с расстоянием от КЗ до преграды $F=250 \mathrm{~mm}$, при котором было проведено большинство экспериментов (как с воздействием магнитного поля на КС, так и в его отсутствие), глубина пробития в случае создания поля хотя и незначительно (в пределах 10\%), но превышала значения, полученные в сопоставимых условиях без электромагнитного воздействия. При других расстояниях $F$ от КЗ до преграды статистика полученных результатов невелика и не позволяет сделать каких-либо определенных выводов, кроме уже прозвучавшего выше о слабом влиянии магнитного поля на пробитие КС.

\section{Обсуждение}

Теоретические исследования $[22,24]$ свидетельствуют, что для заметного замедления развития пластической неустойчивости медной КС и увеличения ее предельного удлинения воздействующее на струю магнитное поле должно иметь индукцию на уровне нескольких десятков тесла. С этими теоретическими оценками вполне коррелирует весьма незначительный прирост пробивного действия КЗ, зафиксированный в проведенных экспериментах при индукции поля до $10 \mathrm{~T}$.

Однако требуют объяснения результаты экспериментов [26], проводившихся примерно по той же схеме (рис. 2,a), в которых при индукции поля всего лишь в пределах $1.7 \mathrm{~T}$ был получен значительно больший прирост пробивного действия КЗ (более 70\%). Причем 

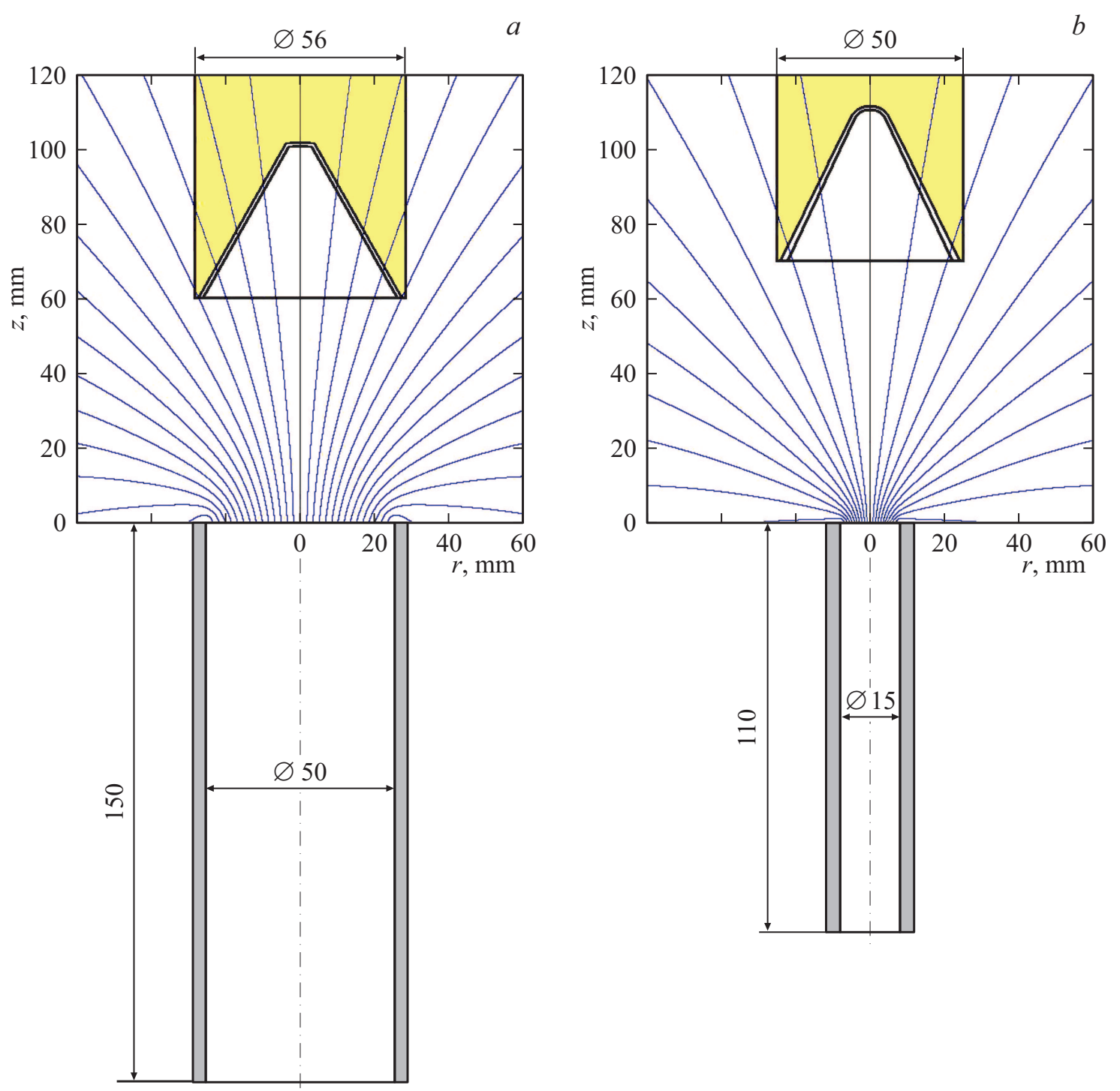

Рис. 6. Линии индукции магнитного поля, создававшегося соленоидами в области облицовки КЗ: $a-$ в экспериментах [26] с индукцией поля в центре соленоида $1.7 \mathrm{~T} ; b-$ в проведенных опытах с индукцией поля в центре соленоида $10.5 \mathrm{~T}$.

на основании осуществленного рентгенографирования КС, прошедших магнитное поле, авторами [26] делается вывод о том, что увеличение пробивного действия достигается именно за счет увеличения предельного удлинения КС. В этих экспериментах использовался К3 близких размеров (диаметром $d_{0}=56 \mathrm{~mm}$ ) также с медной конической облицовкой. Примерно теми же были длина соленоидов $\left(l_{m}=150 \mathrm{~mm}\right)$ и их удаление от основания К3 $\left(h_{m}=60 \mathrm{~mm}\right)$. Различие заключалось лишь в диаметрах использовавшихся соленоидов. В экспериментах [26] диаметр соленоида был примерно равен диаметру КЗ, что в несколько раз больше, чем в проведенных опытах (как отмечалось, в настоящей работе диаметр соленоидов минимизировался с учетом условия свободного прохождения через них КС, целью чего являлось обеспечение возможности получения более сильных магнитных полей).
Вследствие большого диаметра соленоидов при их относительно небольшом удалении от К3 зафиксированный в [26] эффект существенного увеличения предельного удлинения КС может быть связан с воздействием поля не на сформировавшуюся струю, а на схлопывающуюся облицовку, так как создаваемая такими соленоидами перед КЗ область с магнитным полем распространялась и на часть заряда с кумулятивной облицовкой. Согласно же расчетным данным [23], при определенных условиях создание магнитного поля невысокой интенсивности в облицовке КЗ перед его подрывом может приводить не только к снижению пробития КЗ [13-15], но и к его увеличению.

Эффекты, проявляющиеся при взрыве К3 с созданным в его облицовке магнитным полем, обусловлены резким усилением обжимаемого вместе с облицовкой поля в области формирования КС $[32,33]$. Генерирование 


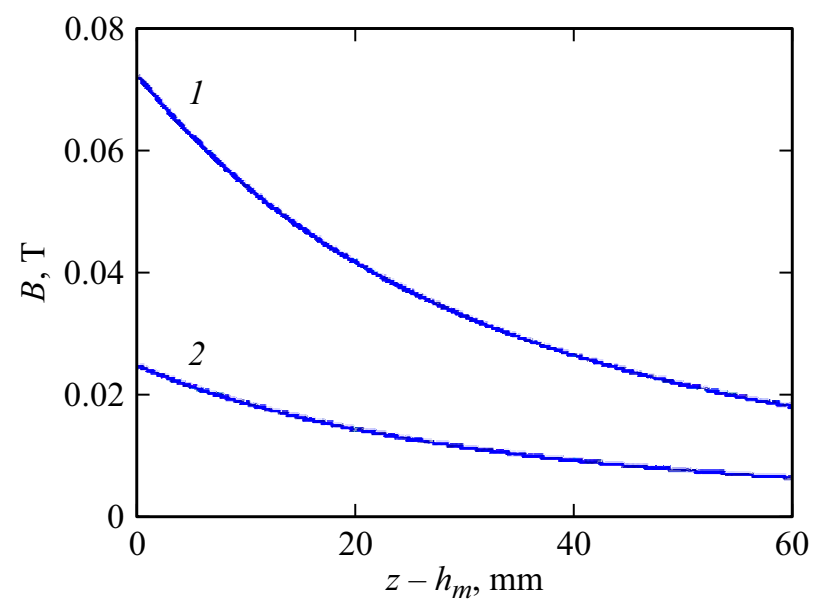

Рис. 7. Распределение магнитной индукции на участке оси симметрии внутри облицовки КЗ: $1-$ в экспериментах [26] с индукцией поля в центре соленоида $1.7 \mathrm{~T} ; 2-$ в проведенных опытах с индукцией поля в центре соленоида $10.5 \mathrm{~T}$.

сильного магнитного поля в материале КС сопровождается действием на струю мощных растягивающих электромагнитных сил, которые способны привести к ее разрушению и радиальному диспергированию с потерей пробивной способности. Это и наблюдалось в экспериментах [13] при индукции начального магнитного поля в облицовке в несколько десятых долей тесла.

Однако усиление магнитного поля в формирующейся КС приводит не только к силовому механическому воздействию на струю, но и к дополнительному разогреву ее материала вихревыми индукционными токами. Нагрев же ведет к снижению прочностных свойств материала КС (эффект термического разупрочнения) и соответственно к замедлению темпа развития пластической неустойчивости струи и увеличению ее предельного удлинения. В [23] было высказано предположение, что при уменьшении индукции начального магнитного поля, создаваемого в облицовке КЗ перед его подрывом до определенного уровня, можно обеспечить термическое разупрочнение материала струи в отсутствие ее разрушения электромагнитными силами. Согласно проведенным в [23] расчетам, указанный уровень магнитной индукции оценивается значением не выше $0.1 \mathrm{~T}$.

На основании [34] были выполнены расчеты распределений магнитных полей, создаваемых в области облицовок КЗ размещенными перед зарядом соленоидами, применительно к условиям проведенных опытов и экспериментов [26]. При задании исходных данных для этих расчетов из проведенной серии опытов были выбраны те, в которых индукция магнитного поля соленоида была максимальна (см. таблицу). В указанных опытах длина соленоида $l_{m}$ и его удаление от основания КЗ $h_{m}$ (рис. $2, a$ ) составляли соответственно $l_{m}=110 \mathrm{~mm}$, $h_{m}=70 \mathrm{~mm}$ при диаметре соленоида $15 \mathrm{~mm}$ и индукции поля в его центре $10.5 \mathrm{~T}$. Для условий экспериментов [26] перечисленные параметры задавались равными $l_{m}=150 \mathrm{~mm}, h_{m}=60 \mathrm{~mm}, 50 \mathrm{~mm}$ - диаметр соленоида, $1.7 \mathrm{~T}$ - магнитная индукция в центре соленоида. И в экспериментах [26], и в проведенных опытах подрыв КЗ производился с некоторым упреждением относительно момента усиления магнитного поля соленоида при разряде через него конденсаторной батареи до максимума с расчетом на то, чтобы максимум поля приходился на промежуток времени движения КС через полость соленоида. Однако в сравнении с полупериодом разряда, составлявшим около $275 \mu \mathrm{s}$ в экспериментах [26], и изменявшимся для соленоидов различного исполнения от 250 до $700 \mu \mathrm{s}$ в представленных опытах (рис. 3, см. таблицу), это упреждение было невелико, так что значение индукции поля в момент подрыва незначительно отличалось от ее значения в максимуме (рис. 4). По этой причине сравнительная оценка параметров магнитных полей, создававшихся в облицовках КЗ, проводилась в предположении максимума поля соленоидов.

На рис. 6 приводится полученная картина линий магнитной индукции в пространстве над соленоидами в месте размещения К3, а на рис. 7 - распределение магнитной индукции на участке оси симметрии внутри облицовок (координата z отсчитывается от обращенного к КЗ торца соленоида). Видно, что, несмотря на существенно более сильное магнитное поле в полости соленоида, магнитное поле в области облицовки КЗ в проведенных опытах было заметно слабее, чем в экспериментах [26], в связи с быстрым убыванием индукции поля по мере удаления от соленоида, обусловленным его небольшим диаметром. Уменьшение магнитной индукции поля у основания КЗ по отношению к магнитной индукции поля в центре соленоида составляло примерно 400 раз в условиях представленных экспериментов и только чуть более 20 раз в условиях экспериментов [26] с использованием соленоидов значительно большего диаметра.

Как показали расчеты, вследствие увеличенного диаметра соленоидов в экспериментах [26] при создании магнитного поля с индукцией 1.7 Т на пути движения КС индукция поля у основания КЗ с облицовкой составляла около 0.08 Т (рис. 7). Это примерно втрое больше индукции поля, возникавшего у основания КЗ в проведенных опытах при индукции поля в центре соленоида $10.5 \mathrm{~T}$. Индукция попутно создававшегося в облицовке КЗ в экспериментах [26] магнитного поля хорошо согласуется со значениями, при которых его отрицательное влияние на пробивное действие КЗ в соответствии с данными [23] может смениться положительным. Как представляется, полученный в [26] прирост пробивного действия КЗ связан именно с присутствием в облицовке КЗ в момент подрыва магнитного поля необходимой интенсивности, а не с его воздействием на растягивающуюся КС. Достижение в этом случае большого положительного эффекта при создании в облицовке КЗ относительно слабого магнитного поля с индукцией всего лишь на уровне $0.1 \mathrm{~T}$, так же как и проявление мощного отрицательного эффекта при индукции поля в облицовке в несколько 
десятых долей тесла [13], не должно вызывать особого удивления. Взрыв КЗ с созданным в его облицовке небольшим начальным магнитным полем организован таким образом, что облицовка в процессе схлопывания сама генерирует сильное поле, воздействующее на формирующуюся КС. Важно только обеспечить необходимый уровень воздействия, выбирая соответствующим образом индукцию начального поля.

Проявлению в экспериментах [26] эффектов, связанных с усилением созданного в облицовке магнитного поля при ее схлопывании, способствовал также и несколько больший диаметр использовавшихся КЗ $\left(d_{0}=56 \mathrm{~mm}\right)$. Захватываемый облицовкой для последующего обжатия магнитный поток был в этих экспериментах больше не только вследствие более сильного магнитного поля, создававшегося в облицовке, но и вследствие ее большего диаметра.

Таким образом, первый довод в пользу выдвинутой гипотезы об истинной причине зафиксированного авторами [26] прироста пробития КЗ состоит в том, что в проведенных по той же схеме опытах с созданием на пути КС в близкой по размерам и положению относительно КЗ зоне даже более сильного магнитного поля, подобного прироста не наблюдалось. При этом в облицовке КЗ в экспериментах [26] попутно создавалось в момент подрыва магнитное поле с существенно большей индукцией.

Есть и второй довод в пользу выдвинутой гипотезы. Он связан с увеличением скорости КС, зафиксированным авторами [26] в опытах с воздействием на струю магнитного поля. При скорости головной части КС в отсутствие поля около $6 \mathrm{~km} / \mathrm{s}$ ее прирост в опытах с наличием поля по данным [26] составлял от 10 до 20\%. Объяснение обнаруженного эффекта было предложено авторами [26] в их работе [29]. Ее основная идея состоит в том, что дополнительное ускорение участки КС приобретают на стадии их входа в магнитное поле соленоида за счет взаимодействия индуцирующихся в материале КС азимутальных вихревых токов с радиальной компонентой магнитного поля соленоида.

Однако представленное в [29] объяснение эффекта увеличения скорости КС не может быть признано корректным. Некорректной является уже его изначальная предпосылка о том, что при входе в область с магнитным полем индукция поля внутри КС совпадает с индукцией внешнего поля, на основании чего определяются индукционные токи в струе. Согласно данным работы [22] (цитируемой авторами [29]), процесс диффузии (проникновения) внешнего магнитного поля в материал растягивающейся КС до момента достижения индукцией поля в струе значения индукции внешнего поля занимает достаточно длительный промежуток времени. Чтобы не быть голословными, обратимся к рис. 8, на котором проиллюстрировано изменение индукции магнитного поля соленоида и индукции поля на оси головного участка КС в зависимости от его текущей координаты $z$

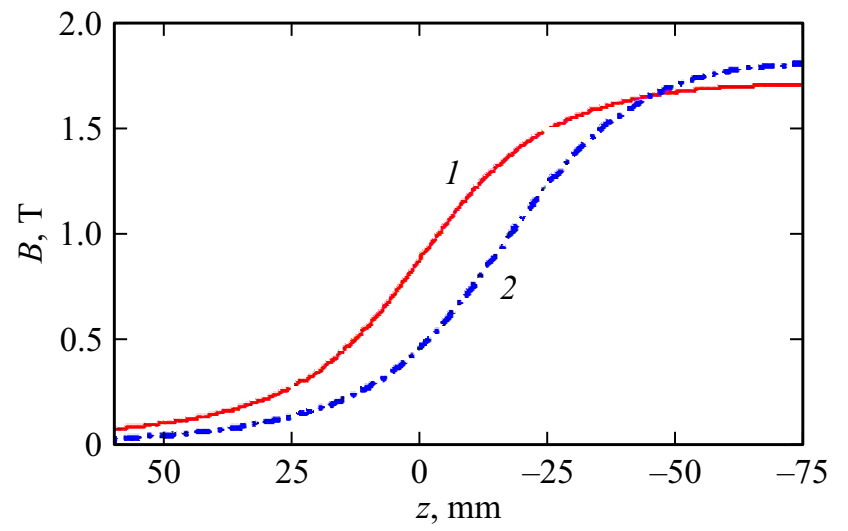

Рис. 8. Проникновение магнитного поля в материал участка КС при его входе в полость соленоида: 1 - изменение магнитной индукции поля соленоида на его оси, 2 - изменение магнитной индукции поля на оси участка КС.

относительно торца соленоида, рассчитанное на основании [22] применительно к условиям экспериментов [26] (согласно приведенным в [26] данным скорость головного участка КС принималась равной $6 \mathrm{~km} / \mathrm{s}$, его начальный радиус составлял $2.14 \mathrm{~mm}$, а начальная скорость осевого деформирования $\left.3.05 \cdot 10^{5} \mathrm{~s}^{-1}\right)$. Видно, что индукция поля в головном участке КС сравнивается с индукцией внешнего поля только когда он уже находится вблизи центра соленоида (ему на рис. 8 соответствует координата $z=-75 \mathrm{~mm}$ ), а до этого момента поле в струе все время слабее внешнего. Ослабление поля в струе происходит вследствие циркуляции в ней азимутальных индукционных токов, которые при входе участка КС в полость соленоида, очевидно, имеют направление, противоположное направлению протекания тока в витках соленоида. Взаимодействие этих индукционных токов с радиальной компонентой магнитного поля соленоида будет приводить не к ускорению, как полагают авторы [29], а, напротив, к торможению участков КС на входе в полость соленоида (рис. 9, $a$ ). Также совершенно очевидно, что торможение это будет крайне слабым и практически незаметным ввиду относительной слабости создававшегося в экспериментах [26] магнитного поля и пренебрежимой малости его радиальной компоненты у оси симметрии на удалении, соответствующем радиусу участка КС. Кстати говоря, и ускорение участка КС на входе в соленоид, если основываться на искаженных представлениях работы [29] об эволюции магнитного поля в струе, тоже должно получаться очень незначительным (по крайней мере, на три порядка меньше, чем было получено в работе). Все дело в том, что при проведении выкладок в [29] были допущены дополнительные просчеты, приведшие, в частности, к тому, что для ускорения участка КС было получено выражение с физической размерностью, отличной от размерности ускорения. 

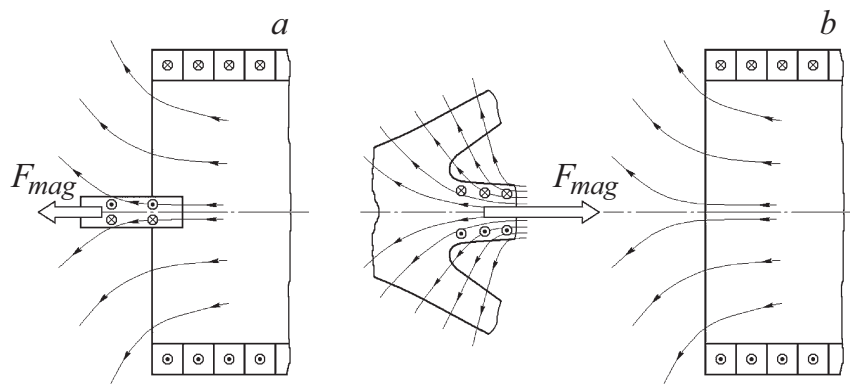

Pис. 9. Осевые магнитные силы, действующие на участок КС при его входе в полость соленоида $(a)$ и на участок формирующейся КС при схлопывании облицовки с созданным в ее материале магнитным полем $(b)$.

Из вышесказанного вытекает несостоятельность предложенного в [29] объяснения эффекта увеличения скорости КС в экспериментах [26] с созданием магнитного поля на пути движения струи. Однако такое объяснение, по крайней мере, на качественном уровне логичным образом укладывается в рамки выдвинутой гипотезы о проявлении в экспериментах [26] эффектов, связанных с присутствием магнитного поля в облицовке КЗ в момент подрыва. Из рис. 6 видно, что размещенный перед КЗ соленоид создает в материале облицовки магнитное поле с вектором индукции, имеющим как осевую, так и радиальную компоненты. В соответствии с известным в магнитной гидродинамике эффектом „вмороженности“ магнитного поля в вещество [31] при схлопывании облицовки радиальная составляющая индукции поля будет возрастать, отслеживая происходящие деформации удлинения частиц облицовки в радиальном направлении. Одновременно в полости облицовки будет происходить обжатие магнитного потока поля с осевой ориентацией, сопровождающееся его усилением (эффект магнитокумулятивного генератора) и диффузией во внутренний слой облицовки, из которого впоследствии формируется КС. Дополнительное усиление поля осевой ориентации в соответствии с эффектом „вмороженности“ должно происходить уже непосредственно в области струеобразования, где частицы формирующейся КС испытывают большие деформации удлинения в осевом направлении [32]. В результате всех этих процессов при схлопывании облицовки в области струеобразования „накачивается“ сильное магнитное поле с осевой и радиальной компонентами вектора индукции. По данным [23] коэффициент усиления поля в материале формирующейся КС оценивается значениями не ниже $10^{2}$. В участке КС, выходящем из области струеобразования с усилившимся магнитным полем той же ориентации, что и поле соленоида, должны циркулировать азимутальные индукционные токи, имеющие то же направление, что и токи в витках соленоида. Взаимодействие этих индукционных токов с осевой компонентой магнитного поля приводит к появлению радиальных растягивающих сил, за счет действия которых может произойти разрушение КС с ра- диальным диспергированием ее материала. Результатом же взаимодействия индукционных токов с радиальной компонентой поля являются осевые силы, стремящиеся „отбросить“ материал формирующегося участка КС от области струеобразования (рис. 9, $b$ ). Вследствие значительного усиления поля в области струеобразования эти осевые силы будут гораздо больше сил, действующих на участок КС при входе в полость соленоида, и, как представляется, по этой причине способны обеспечить заметный прирост скорости КС.

Таким образом, второй довод в пользу выдвинутой гипотезы о проявлении в экспериментах [26] эффектов, связанных с усилением созданного в облицовке КЗ магнитного поля при ее схлопывании, состоит в том, что в этом случае получает правдоподобное объяснение эффект зафиксированного авторами [26] увеличения скорости КС.

Подытоживая проведенное обсуждение, сформулируем еще раз его основной вывод. Благодаря удачному стечению обстоятельств авторы [26], проводя эксперименты с воздействием магнитного поля на КС на ранней стадии ее инерционного удлинения, сами того не подозревая, создавали попутно в облицовке КЗ магнитное поле с параметрами, при которых его последующее усиление при схлопывании облицовки положительным образом отражалось на пробитии КЗ, приводя к увеличению предельного удлинения формировавшихся КС вследствие термического разупрочнения их материала.

\section{Заключение}

В проведенных экспериментах с воздействием продольного магнитного поля на растягивающуюся КС прирост пробивного действия КЗ составил не более $10 \%$, что значительно меньше, чем в аналогичных экспериментах [26]. Сравнительный анализ постановки и результатов обеих серий экспериментов позволяет с высокой степенью вероятности предположить, что данные работы [26] являются первым экспериментальным подтверждением очень интересного и практически значимого эффекта, предсказанного в [23] теоретически, и заключающегося в увеличении пробивного действия КЗ при создании аксиального магнитного поля в его облицовке.

\section{Благодарности}

Работа посвящается памяти Вячеслава Михайловича Маринина, внесшего большой вклад в исследования кумулятивного эффекта взрыва.

\section{Конфрликт интересов}

Авторы заявляют, что у них нет конфликта интересов. 


\section{Список литературы}

[1] Лаврентьев М.А. // Успехи математических наук. 1957. T. 12. Вып. 4(76). С. 41-56.

[2] Walters W.P., Zukas J.A. Fundamentals of Shaped Charges. NY:: Wiley, 1989. 398 p.

[3] Chou P.C., Fiis W.J. // Propellants, Explosives, Pyrotechnics. 1986. Vol. 11. N 4. P. 99-114.

[4] Физика взрыва / Под ред. Л.П. Орленко. В 2-х т. Т. 2. М.: Физматлит, 2004. 656 с.

[5] Бабкин А.В., Ладов С.В., Маринин В.М., Федоров С.В. // ПМТФ. 1997. Т. 38. № 2. C. 3-9. [Babkin A.V., Ladov S.V., Marinin V.M., Fedorov S.V. // J. Appl. Mech. Tech. Phys. 1997. Vol. 38. N 2. P. 171-176.]

[6] Walters W.P., Summers R.L. // Propellants, Explosives, Pyrotechnics. 1993. Vol. 18. N 5. P. 241-246.

[7] Petit J. // J. Appl. Phys. 2005. Vol. 98. N 12. P. 123521.

[8] Svirsky O.V., Vlasova M.A., Korotkov M.I., Krutyakov V.A., Toropova T.A. // Intern. J. Impact Engineer. 2003. Vol. 29. N 1-10. P. 683-690.

[9] Hancock S.L. // Intern. J. Impact Engineer. 1999. Vol. 23. N 1(1). P. 353-363.

[10] Бабкин А.В., Ладов С.В., Маринин В.М., Федоров С.В. // ПМТФ. 1999. Т. 40. № 4. C. 25-35. [Babkin A.V., Ladov S.V., Marinin V.M., Fedorov S.V.// J. Appl. Mech. Tech. Phys. 1999. Vol. 40. N 4. P. 571-580.]

[11] Walsh J.M. // J. Appl. Phys. 1984. Vol. 56. N 7. P. 1997-2006.

[12] Romero L.A. // J. Appl. Phys. 1989. Vol. 65. N 8. P. $3006-$ 3016.

[13] Федоров С.В., Бабкин А.В., Ладов С.В. // Физика горения и взрыва. 1999. Т. 35. № 5. С. 145-146. [Fedorov S.V., Babkin A.V., Ladov S.V. // Combustion, Explosion, and Shock Waves. 1999. Vol. 35. N 5. P. 598-599.]

[14] Shvetsov G., Matrosov A., Fedorov S., Babkin A., Ladov S. // PPPS 2001 - Pulsed Power Plasma Science. 2001. 2015. Vol. 1. 1002023. P. 182-186.

[15] Федоров С.В., Бабкин А.В., Ладов С.В. // ЖТФ. 2003. Т. 73. Вып. 8. C. 111-117. [Fedorov S.V., Babkin A.V., Ladov S.V. // Tech. Phys. 2003. Vol. 48. N 8. P. 1047-1052.]

[16] Pollock C.E. In: Megagauss Magnetic Field Generation and Pulsed Power Applications. NY: Nova Sci. Publ., 1994. P. 309-316.

[17] Матросов А.Д., Швецов Г.А. // ПМТФ. 1996. Т. 37. № 4. C. 9-14. [Matrosov A.D., Shvetsov G.A. // J. Appl. Mech. Tech. Phys. 1996. Vol. 37. N 4. P. 464-469.]

[18] Littlefield D.L. // Phys. Fluid. A: Fluid Dynamics. 1991. Vol. 3. N 6. P. $1666-1673$.

[19] Littlefield D.L. // Phys. Fluid. 1994. Vol. 6. N 8. P. 2722-2729.

[20] Appelgren P., Skoglund M., Lundberg P., Westerling L., Larsson A., Hurtig T. // J. Appl. Mech. 2010. Vol. 77. N 1. P. 1-7.

[21] Littlefield D.L. // Phys. Fluid. A: Fluid Dynamics. 1991. Vol. 3. N 12. P. 2927-2935.

[22] Федоров С.В., Бабкин А.В., Ладов С.В. // Инженернофизический журнал. 2001. Т. 74. № 2. С. 79-86. [Fedorov S.V., Babkin A.V., Ladov S.V. // J. Engineer. Phys. Thermophysics. 2001. Vol. 74. N 2. P. 364-374.]

[23] Федоров С.В. // ПМТФ. 2016. Т. 57. № 3. С. 108-120. [Fedorov S.V. // J. Appl. Mech. Tech. Phys. 2016. Vol. 57. N 3. P. 483-493.]
[24] Федоров С.В., Болотина И.А., Струков Ю.А. // Вестник МГТУ им. Н.Э. Баумана. Сер. Естественные науки. 2018. № 2. C. 39-59. [Fedorov S.V., Bolotina I.A., Strukov Yu.A. // Herald of the Bauman Moscow State Tech. Univ., Nat. Sci. 2018. N 2. P. 39-59.]

[25] Ma B., Huang Z.-X., Zu X.-D., Xiao Q.-Q. // Intern. J. Impact Engineer. 2016. Vol. 98. P. 88-96.

[26] Ma B., Huang Z., Guan Z., Zu X., Jia X., Xiao Q. // Intern. J. Impact Engineer. 2018. Vol. 113. P. 54-60.

[27] Xiao Q.-Q., Huang Z.-X., Zu X.-D., Jia X. // Propellants, Explosives, Pyrotechnics. 2016. Vol. 41. N 1. P. 76-83.

[28] Ayisit O. // Intern. J. Impact Engineer. 2008. Vol. 35. N 12. P. 1399-1404.

[29] Ma B., Huang Z., Guan Z., Jia X., Xiao Q., Zu X. // Intern. J. Mech. Sci. 2017. Vol. 133. P. 283-287.

[30] Бабкин А.В., Маринин В.М., Федоров С.В. // Оборонная техника. 1993. № 9. С. 40-46.

[31] Ландау Л.Д., Лифиии, Е.М. Электродинамика сплошных сред. М.: Наука, 1982. 621 с.

[32] Федоров С.В. // Физика горения и взрыва. 2005. Т. 41 № 1. C. 120-128. [Fedorov S.V. // Combustion, Explosion, and Shock Waves. 2005. Vol. 41. N 1. P. 106-113.]

[33] Федоров С.В. // Боеприпасы и высокоэнергетические конденсированные системы. 2008. № 2. С. 73-80.

[34] Алиевский Б.Л., Орлов В.Л. Расчет параметров магнитных полей осесимметричных катушек: Справочник. М.: Энергоатомиздат, 1983. 112 с. 